\title{
Failure of delayed nonsynaptic neuronal plasticity underlies age-associated long-term associative memory impairment
}

\author{
Shawn N Watson ${ }^{1}$, Tara E Risling ${ }^{1}$, Petra M Hermann ${ }^{1}$ and Willem C Wildering ${ }^{1,2^{*}}$
}

\begin{abstract}
Background: Cognitive impairment associated with subtle changes in neuron and neuronal network function rather than widespread neuron death is a feature of the normal aging process in humans and animals. Despite its broad evolutionary conservation, the etiology of this aging process is not well understood. However, recent evidence suggests the existence of a link between oxidative stress in the form of progressive membrane lipid peroxidation, declining neuronal electrical excitability and functional decline of the normal aging brain. The current study applies a combination of behavioural and electrophysiological techniques and pharmacological interventions to explore this hypothesis in a gastropod model (Lymnaea stagnalis feeding system) that allows pinpointing the molecular and neurobiological foundations of age-associated long-term memory (LTM) failure at the level of individual identified neurons and synapses.

Results: Classical appetitive reward-conditioning induced robust LTM in mature animals in the first quartile of their lifespan but failed to do so in animals in the last quartile of their lifespan. LTM failure correlated with reduced electrical excitability of two identified serotonergic modulatory interneurons (CGCs) critical in chemosensory integration by the neural network controlling feeding behaviour. Moreover, while behavioural conditioning induced delayed-onset persistent depolarization of the CGCs known to underlie appetitive LTM formation in this model in the younger animals, it failed to do so in LTM-deficient senescent animals. Dietary supplementation of the lipophilic anti-oxidant a-tocopherol reversed the effect of age on CGCs electrophysiological characteristics but failed to restore appetitive LTM function. Treatment with the SSRI fluoxetine reversed both the neurophysiological and behavioural effects of age in senior animals.

Conclusions: The results identify the CGCs as cellular loci of age-associated appetitive learning and memory impairment in Lymnaea and buttress the hypothesis that lipid peroxidation-dependent depression of intrinsic excitability is a hallmark of normal neuronal aging. The data implicate both lipid peroxidation-dependent nonsynaptic as well as apparently lipid peroxidation-independent synaptic mechanisms in the age-dependent decline in behavioural plasticity in this model system.
\end{abstract}

Keywords: Cognitive impairment, Neural plasticity, Neuronal excitability, Oxidative stress, Lipid peroxidation, a-tocopherol, Mollusc, Classical conditioning, Serotonin, Lymnaea stagnalis

\footnotetext{
* Correspondence: wilderin@ucalgary.ca

'Department of Biological Sciences, Faculty of Science, University of Calgary, Calgary, AB T2N 1 N4, Canada

${ }^{2}$ Department of Physiology and Pharmacology, Faculty of Medicine,

Hotchkiss Brain Institute, University of Calgary, Calgary, AB T2N 4 N1, Canada
} 


\section{Background}

Age-associated learning and memory impairment is a signature of the normal aging process in humans and animals of diverse phylogenetic background [1-6]. In contrast to age-associated neurodegenerative diseases, functional decline due to normal brain aging involves subtle physiological changes in neuron and neuronal network function rather than a widespread loss of neurons [6-10]. Understanding these processes is essential to develop effective strategies to deal with the problems associated with old age. Yet, molecular and cellular dimensions of the normal brain aging are still incompletely understood. In the current study we continue our exploration of the hypothesis that declining performance of the aging brain is associated with a reduction in neuronal electrical excitability resulting from oxidative stress occurring at the level of the neuronal plasmamembrane. The neuronal plasmamembrane, due to its high polyunsaturated fatty acid (PUFA) content, is particularly prone to non-enzymatic oxidative insult [11-13]. Moreover, the idea that oxidative stress is an important agent of biological aging of the brain has substantial support [14-18] and a growing body of evidence suggests that a progressive decline in intrinsic electrical excitability of aging neurons is a significant aspect of the problem $[3,6$ 10].

In our studies we use the pond snail Lymnaea stagnalis as model system of age-associated memory impairment [6,19]. Gastropod mollusks like Lymnaea have a relatively simple nervous system containing many identified neurons and precisely mapped, functionally characterized neuronal circuits that allow one to trace the neural basis of whole animal behavioural and physiological functions to the level of single neurons and synapses [19]. In the current study we utilize an established and widely studied classical appetitive reward-conditioning paradigm involving chemosensory conditioning of the animals' feeding behaviour (i.e., "rasping") to investigate neurophysiological correlates of age-associated changes in learning and memory abilities [6,20-24]. The neurobiological substrate of Lymnaea's feeding behaviour and important details of the mechanisms of plasticity underlying the expression of appetitive long-term memory (LTM) are known in detail [24,25]. Specifically, the expression of associative LTM depends on presynaptic facilitation arising from a behavioral conditioning-induced persistent depolarization of a pair of state-controlling serotonergic interneurons, the cerebral giant cells (CGCs) that play a permissive role in feeding behavior but have no direct role in the generation of the rhythmic feeding pattern [24]. The persistent depolarization affects the synaptic outputs of the CGCs within the cerebral ganglia. This underlies the presynaptic facilitation of the sensory pathways to the feeding command interneurons. One of its consequences is that throughput of peripheral chemosensory afferent information to the feeding circuit is altered [24].

Our previous work has linked age-associated appetitive LTM impairment in Lymnaea stagnalis to a reduction in intrinsic excitability of the CGCs [6]. This change in CGC response characteristics is of a magnitude likely to upset the cells' control functions and, possibly, their ability to express the behavioral conditioning-induced persistent depolarization underlying appetitive LTM in this model system [6]. Recent studies have linked ageassociated decline of electrical excitability of another identified Lymnaea neuron to lipid peroxidation $[3,19]$. These studies also indicate that this neuro-physiological effect of age is reversible by treatment with the lipophilic anti-oxidant $\alpha$-tocopherol (vitamin E) [3,19]. Alphatocopherol is the main anti-oxidant agent operating in the lipid bilayer domain and a cell's primary defense against the progression of lipid-peroxidation. The current study examines whether the finding that treatment with $\alpha$-tocopherol reverses electrophysiological phenomena associated with old age can be extrapolated to the CGCs and whether such correction is sufficient to restore appetitive learning and memory capability of old Lymnaea to the level typical of young animals.

To this end we compared learning abilities and CGC electrophysiological parameters of old LTM-impaired animals that were put on a $\alpha$-tocopherol enriched diet with similar animals that were fed a standard diet with a lower $\alpha$-tocopherol content. In addition, mindful of the notion that LTM deficiency in this model possibly arises from a failure of serotonin release by the CGCs, we tested the impact of the selective serotonin reuptake inhibitor (SSRI) fluoxetine on the same electrophysiological and behavioural parameters in old LTM-impaired animals. The data we present here reveals an intriguing difference in $\alpha$-tocopherol's and fluoxetine's ability to reverse electrophysiological and behavioural effects of age. Our data suggests that restoration of neuronal electrophysiological response characteristics to a young mature condition alone is not sufficient to return appetitive behavioural plasticity of senescent animals to the receptive state of younger animals. As discussed, the data provides arguments that lipid peroxidation-dependent non-synaptic as well as lipid peroxidation-independent synaptic factors play a role in this model system of age-associated learning and memory impairment.

\section{Results}

Age-associated appetitive LTM breakdown correlates with failure of behavioural-conditioning induced CGC depolarization

Our central hypothesis holds that age-associated appetitive LTM failure involves a decline in electrical 
excitability of the CGCs resulting in a loss of these cells' capacity for learning induced persistent membrane depolarization. To assess this idea, LTM of junior and senior snails was evaluated using a single-day, multi-trial, non-aversive appetitive-conditioning assay (Figure 1A) followed by electrophysiological evaluation of CGC excitability in the isolated CNS.

Junior $(\mathrm{n}=35)$ and senior $(\mathrm{n}=43)$ snails were assigned at random to two test groups. One group was submitted to behavioural conditioning by means of paired application

A
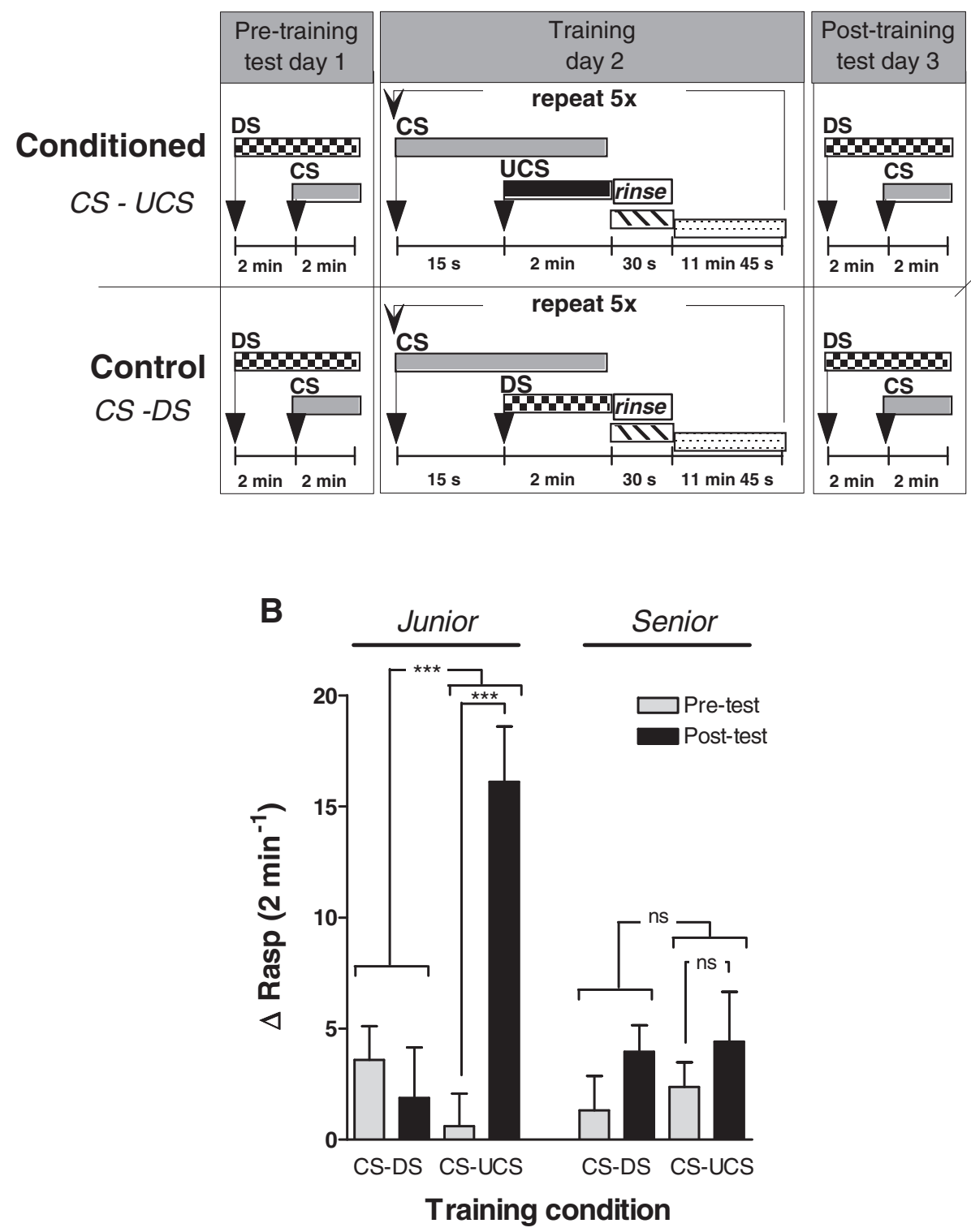

Figure 1 Long-term memory assessment in Junior and Senior animals. A: Long-term memory performance was determined using a single day, multi-trial, non-aversive, appetitive conditioning assay. On day 1, prior to behavioural conditioning animals were tested ("Pre-training test") by the addition of a disturbance stimulus (DS, pond water), counting the number of rasps for 2 minutes followed by the application of the conditioned stimulus (CS, 4 ppm n-amyl acetate) and counting the number of rasps over the following 2 minutes. Conditioning occurred on day 2 and consisted of pairing the CS with the unconditioned stimulus (UCS; $0.4 \%$ sucrose) which was repeated 5 times. A control (unconditioned) group received a similar timed combination of CS and DS. On day 3 animals were subjected to a post-training test protocol identical to the pretraining test conditions. B: Junior and senior animals were randomly assigned to either control or conditioned groups. There was a robust response to conditioning (CS-UCS) in junior animals as displayed by a significant increase in the $\Delta$ rasp values in the post-training test. In contrast, none of the conditioned senior animals and unconditioned (CS-DS) control junior or senior animals responded with significant feeding movements in the post-training test. These results are indicative of LTM impairment in senior snails. ${ }^{* *}=\mathrm{p}<0.001$, ns $=$ non-significant. 
of amyl acetate (the conditioned stimulus or CS) and sucrose (the unconditioned stimulus or UCS). Animals treated this way will be denoted by the abbreviation CS + UCS throughout the text. The second group functioned as control for stimulus application. In this case the UCS stimulus was replaced by application of water (i.e., vehicle-only disturbance control or DS). Animals treated in this manner are signified by the abbreviation CS + DS.

As observed in our previous study [6], there was a significant interaction between age and behavioural conditioning (Figure 1B; Age $\mathrm{x}$ Training $\mathrm{x} \Delta$ rasp, $\left.\mathrm{F}_{1,74}=13.779, \mathrm{p}<0.001\right)$. This interaction arose from the fact that junior, but not senior animals displayed robust conditioned feeding responses after conditioning (CS + UCS) compared to their aged-matched controls $\left(\mathrm{F}_{1,74}=23.275, \mathrm{p}<0.0001\right.$ and $\mathrm{F}_{1,74}=0.0347, \mathrm{p}=0.85$ for junior and senior animals respectively).

Electrophysiological assessment of the CGCs in these animals after training revealed substantial differences in resting membrane potential and spontaneous activity between test groups (Figures 2A, B and C). Spontaneous action potential activity differed significantly between junior and senior animals but not between the behaviourally conditioned animals and their aged-matched controls (Figure 2B; Age $\mathrm{x}$ Training $\mathrm{F}_{1,41}=25.526$, $\mathrm{p}<0.001$; and Training within age $\mathrm{F}_{1,41}=0.068, \mathrm{p}=0.80$ for junior CNS's and $\mathrm{F}_{1,41}=1.179, \mathrm{p}=0.28$ for senior CNS's respectively).

On average, the resting membrane potential of CGCs was more hyperpolarized in senior CNS's than that of their junior counterparts independent of their behavioural training status (Figure 2C; $\mathrm{n}=45$, Mann-Whitney $\mathrm{Z}=3.595, \mathrm{p}<0.001$ ). Moreover, comparison of resting membrane potentials measured in CGCs of CNS preparations from behaviourally conditioned (CS + UCS) with their respective control groups $(C S+D S)$ within each of the age groups, showed that CGC resting membrane potential of conditioned (CS + UCS) junior snails was more depolarized compared to the junior control $(C S+D S$ ) animals (Figure 2C; $n=23$, Mann-Whitney $\mathrm{Z}=-3.728, \mathrm{p}<0.001)$. In contrast, behavioural conditioning had no effect on CGC resting membrane potential in senior snails (Figure $2 \mathrm{C} ; \mathrm{n}=23$, Mann-Whitney $\mathrm{Z}=-0.894, \mathrm{p}=0.37$ ). Together, these data are consistent with the ideas proposed by Kemenes et al. [24] that training-induced depolarization of the CGC is an element of LTM in this appetitive learning model and point towards breakdown of this mechanism as a factor in appetitive LTM impairment observed in aged snails.

Dietary supplementation of a-tocopherol reverse effect of age on CGC excitability but fails to rescue appetitive LTM The data presented above show that appetitive LTM failure in aged animals is associated with a very prominent reduction in action potential activity in the CGC's. Previous studies suggest that the suppression of action potential activity observed in aged Lymnaea neurons is associated with a trend towards more prominent action potential accommodation linked to progressive lipid peroxidation [3]. As a consequence neurons can no longer support sustained periods of elevated spiking activity. Thus, stimulus response characteristics of Lymnaea neurons likely change with age, possibly to the extent that mechanisms of activity-dependent plasticity are affected. Since treatment of aged isolated CNS's with $\alpha$-tocopherol overturned the age-associated drop in neuronal excitability we tested this compound's efficacy in restoring appetitive LTM function of old animals. For this purpose, 17 aged animals were fed a $\alpha$-tocopherol enriched diet for two months while another group of 17 animals was fed the same diet without additional $\alpha$-tocopherol. Behavioural assessment confirmed that all animals were LTM deficient prior to dietary intervention (Figure 3A; $F_{1,32}=0.199$, $\mathrm{p}=0.66$ ). Spontaneous background rasping frequency declined slightly but significantly over the course of the two month dietary intervention due to an, at this moment unknown cause. Importantly, this effect was independent of the dietary composition the animals were fed (Figure 3C; Diet $\mathrm{x}$ Time $\mathrm{F}_{1,32}=0.043, \mathrm{p}=0.84$; Time $\mathrm{F}_{1,32}=9.950, \mathrm{p}<0.001$; Diet $\mathrm{F}_{1,32}=0.736, \mathrm{p}=0.40$ ). Contrary to our expectations, dietary supplementation of $\alpha$-tocopherol failed to restore LTM function in these aged animals (Figure 3B; Treatment $\mathrm{x}$ Training $\mathrm{F}_{2,28}=0.018, \mathrm{p}=0.98$ ).

Yet, intracellular recordings performed on isolated CNS's dissected from these same animals after completion of the behavioural trials revealed a positive effect of diet on action potential activity of CGC's (Figures 4A and B, Diet, $\left.\mathrm{F}_{1,20}=9.511, \mathrm{p}<0.01\right)$ and $\mathrm{CGC}$ resting membrane potential (Figure 4C; Mann-Whitney $Z=-3.430$, $\mathrm{p}<0.001$ ). No evidence was found of an effect of behavioural conditioning on either CGC spiking activity (Figure 4B; $\mathrm{F}_{1,20}=1.297, \mathrm{p}=0.27$ ) or resting membrane potential (Figure 4C; Mann-Whitney; $\mathrm{Z}=-0.614, \mathrm{p}=0.54$ and $Z=0.508, p=0.61$ for vehicle-only and $\alpha$-tocopherol treated animals respectively). Thus, feeding aged animals a $\alpha$-tocopherol enriched diet appears to restore excitability and resting membrane potential of old CGCs to a condition found in young LTM-competent animals, but failed to rejuvenate appetitive LTM functionality.

Aged animals do normally not show any motor and/or chemosensory deficits [6]. However, it is possible that dietary supplementation with $\alpha$-tocopherol affects chemosensory and/or motor functions. To test this possibility a separate set of aged animals were fed an $\alpha$-tocopherol enriched diet for two months while a control group was fed the same diet without additional $\alpha$-tocopherol. Subsequently, we determined the feeding response upon sucrose 

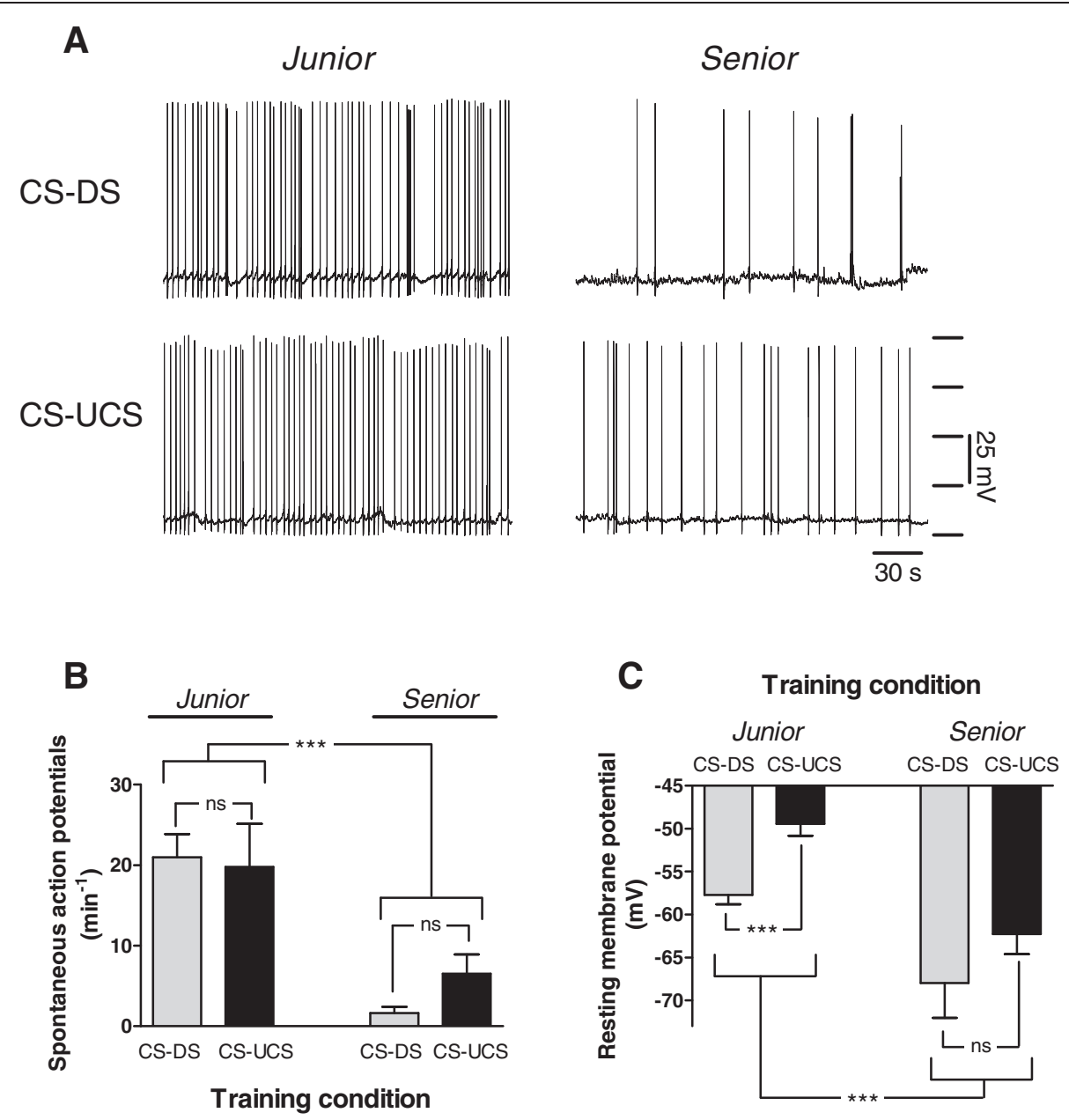

Figure 2 Electrophysiological assessment of CGCs in Junior and Senior animals. A. Examples of intracellular recording of spontaneous electrical activity in CGCS of junior and senior conditioned (CS-UCS) and unconditioned control (CS-DS) animals. B. Average number of spontaneous action potentials of CGCs in both junior and senior conditioned and control animals. Aged CGCs showed a significantly lower spontaneous action potential firing rate than junior CGCs No significant difference was observed between the control and conditioned groups within each age category. C. Resting membrane potential of junior CGCs was more depolarized compared with senior CGCs. Behavioural conditioning further depolarized resting membrane potential in junior but not in senior animals.. ${ }^{*}=p<0.05,{ }^{* * *}=p<0.001$, ns $=$ non-significant.

application and measured by means of extracellular recording techniques the activity of afferents in the superior lip nerve in a semi-intact preparation before and after amyl acetate application.

Figure 5 shows that dietary supplementation with $\alpha$-tocopherol did not affect sensory perception of amyl acetate. Application of amyl acetate $(4 \mathrm{ppm})$ induced an immediate and significant increase in electrical activity of the afferents in the superior lip nerve. This effect was similar in both treatment groups $(\mathrm{n}=8$ for both groups, Figures 5A, B; ANOVA time vs treatment $\mathrm{F}_{1,14}=0.841$, $\mathrm{p}=0.37$; contrast $-\alpha$-tocopherol pre application vs post application $\mathrm{F}_{1,14}=18.489, \mathrm{p}<0.001$; contrast $+\alpha$-tocopherol pre application vs post application $\mathrm{F}_{1,14}=9.017, \mathrm{p}<0.01$ ). In addition, examining rasping responses after sucrose stimulation in intact animals showed that diet had no effect on chemosensory or motor function. That is, while none of the animals responded with rasping movements after application of the disturbance stimulus (DS), application of sucrose $(0.4 \%$ final concentration) induced a robust feeding response in both $\alpha$-tocopherol fed animals $(n=9)$ and their controls $(n=9$; Figure 5C; ANOVA solution vs treatment $F_{1,16}=0.412, p=0.53$; contrast sucrose response $\alpha$-tocopherol vs control $F_{1,16}=0.539, p=0.47$ ). Thus, dietary supplementation with $\alpha$-tocopherol does not affect feeding network related chemosensory or motor functions.

\section{Fluoxetine treatment reverses effects of age on appetitive} LTM and CGC excitability

The data presented in the preceding sections are consistent with conclusions of Kemenes et al. [24] that CGC 


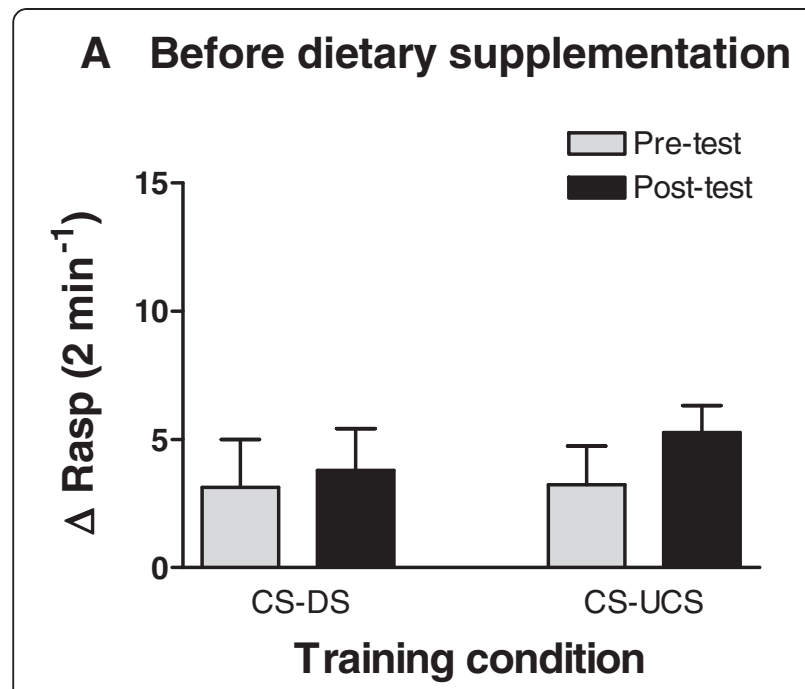

B After dietary supplementation

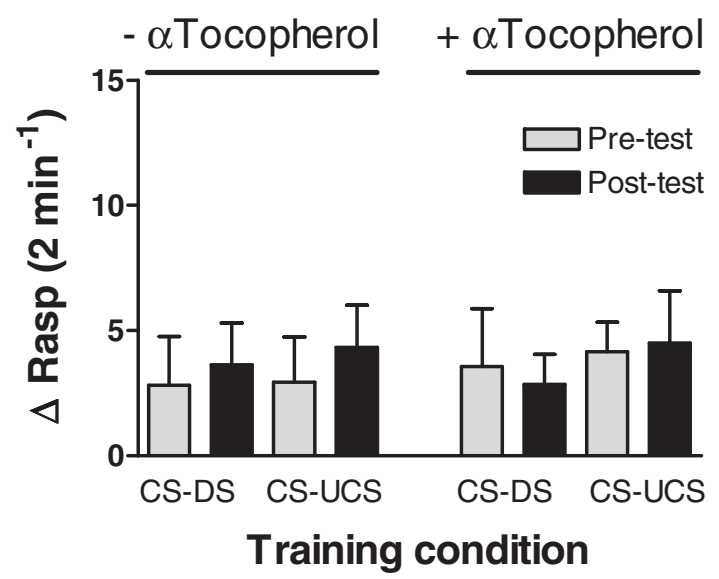

C

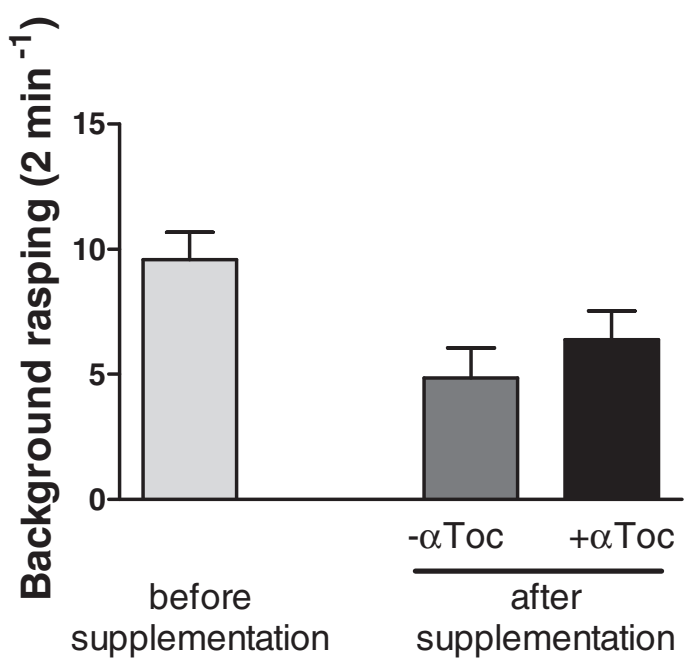

Figure 3 Effect of dietary a-tocopherol supplementation on LTM performance in senior animals. A. Long-term memory assessment of senior snails before the start of dietary

supplementation with a-tocopherol. None of the control (CS-DS) or conditioned (CS-UCS) animals displayed a significant increase in the $\Delta$ Rasp value indicative of LTM impairment. B. Long-term memory assessment of senior snails following 2 months of a-tocopherol dietary supplementation (+ aTocopherol) or vehicle only (aTocopherol). Neither a-tocopherol or vehicle treated animals displayed an improvement in LTM performance C. Comparison of spontaneous background rasping rates reveals no significant differences between animals treated with a-tocopherol (+ aToc) or vehicle only (-aToc).

depolarization is both a necessary and sufficient condition for the expression of appetitive LTM in nonsenescent animals [24]. However, the above observation that dietary intervention succeeded in recreating the electrophysiological conditions in old animals normally associated with appetitive LTM, yet did not restore LTM functions suggest a failure of additional mechanisms involved in depolarization-induced presynaptic facilitation of CGC terminals in old animals. This idea is consistent with evidence presented by Patel et al. that CGC excitation-secretion coupling characteristics change with age [26]. Prompted by the latter authors evidence that the SSRI fluoxetine appears to reverse this effect of age, we tested this compound's ability to reverse the effects of age on appetitive LTM function and CGC electrophysiological characteristics of old LTM-impaired animals.

In these experiments 30 senior animals received before behavioural conditioning a single $50 \mu$ injection of fluoxetine in their body cavity to create an effective hemolymph concentration of fluoxetine of $\sim 100 \mathrm{nM}$. A second group of 30 senior animals subjected to the same experimental protocol received vehicle-only injections (i.e., water). Behavioural and electrophysiological assessments of these animals proceeded as described previously.

Fluoxetine-treated behaviourally-conditioned (CSUCS) animals displayed robust conditioned feeding responses, while no such response was observed in the vehicle-only injected conditioned animals or all unconditioned (CS-DS) animals (Figure 6A; Treatment $x$ Training $\mathrm{x} \Delta$ rasp, $\mathrm{F}_{1,55}=4.371, \mathrm{p}<0.05$; Training $\mathrm{x} \Delta$ rasp within fluoxetine treated animals, $F_{1,55}=15.997$, $\mathrm{p}<0.001 ; \Delta$ rasp pre-training vs $\Delta$ rasp post-training for fluoxetine treated CS-UCS group, $F_{1,55}=25.157$, $\mathrm{p}<0.0001$; Training $\mathrm{x} \Delta$ rasp within vehicle- treated animals, $\mathrm{F}_{1,55}=0.998, \mathrm{p}=0.32 ; \Delta$ rasp pre-training vs $\Delta$ rasp post-training for vehicle-treated CS-UCS group, $\mathrm{F}_{1,55}=0.008, \mathrm{p}=0.93$ ). Importantly, fluoxetine injection had no effect on spontaneous baseline rasping frequency (Figure 6B; Treatment $\mathrm{x}$ Time $\mathrm{F}_{1,57}=0.033, \mathrm{p}=0.86$; Time $\mathrm{F}_{1,57}=3.334, \mathrm{p}=0.07$; Treatment $\mathrm{F}_{1,57}=1.6805$, 


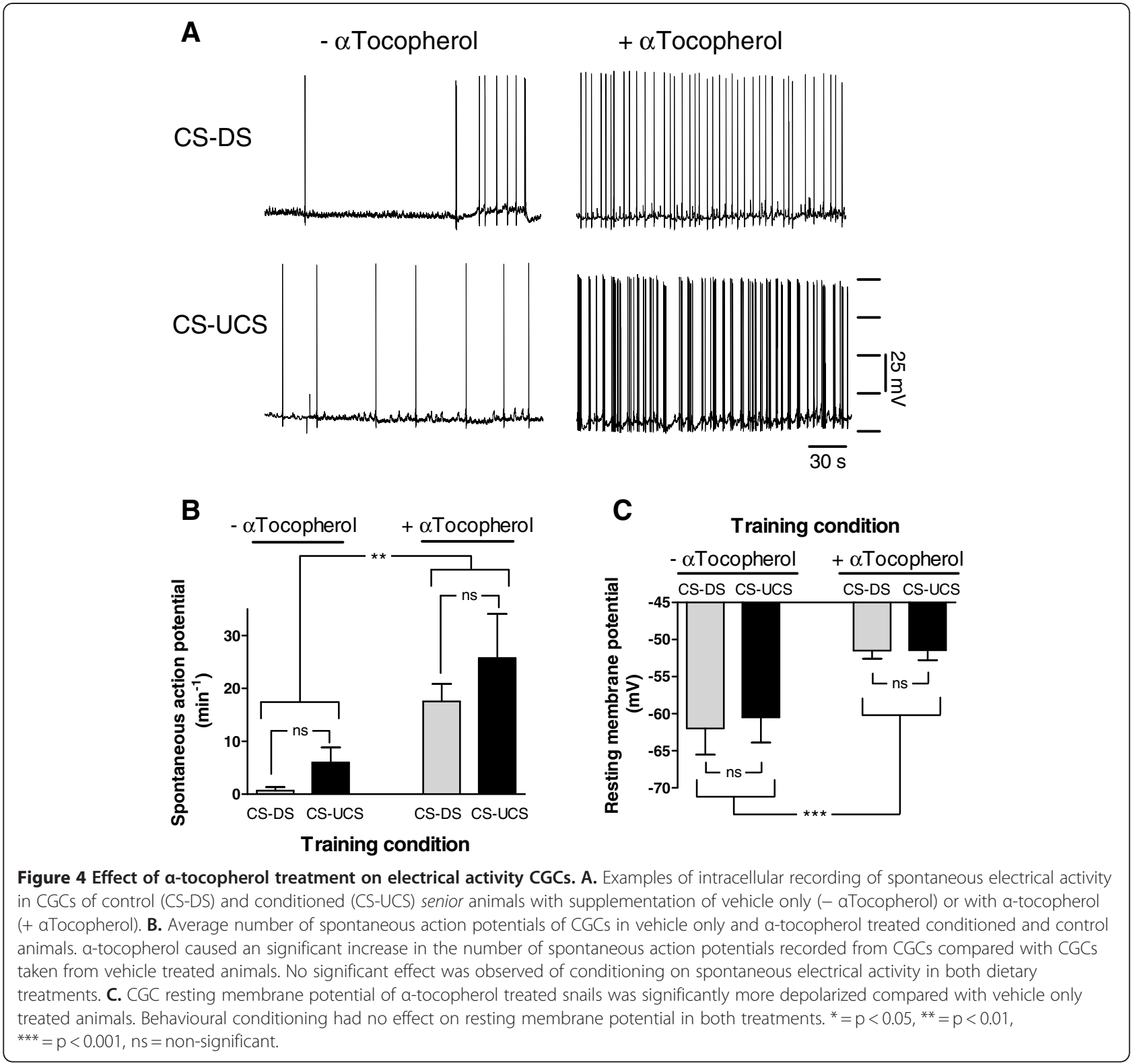

$\mathrm{p}=0.20)$. However, it is still remotely possible that Fluoxetine-treated behaviourally-conditioned (CS-UCS) animals increased their feeding movements due to nonassociative effects. If this is the case, one would expect after training an increase in the number of rasps due to for instance handling, changing environment and/or upon application of a (neutral) solution. Yet, comparing the feeding response upon DS application (i.e., $\Delta \operatorname{Rasp}_{\mathrm{DS}}=$ \#rasps after DS - \#rasps before DS) before and after training indicate no significant changes in the number of rasps in the unconditioned (CS-DS) or the conditioned (CS-UCS) animals in either of the two treatment groups (Figure 6C; Time $\mathrm{x}$ Treatment $\mathrm{x}$ Training $\mathrm{F}_{1,55}=1.876, \mathrm{p}=0.18$; Time $\mathrm{x}$ Treatment $\mathrm{F}_{1,55}=0.736$, $\mathrm{p}=0.39$; Time $\mathrm{x}$ Training $\mathrm{F}_{1,55}=0.041, \mathrm{p}=0.84$ ). Together, this clearly indicates that handling, a change in environment nor the application of a solution (DS) induces non-associative feeding responses. Thus, only in (Fluoxetine) conditioned animals (CS-UCS) and only application of the conditioned stimulus is capable of evoking a significant increase in rasping movements.

Electrophysiological assessment of CGC excitability proceeded after completion of the behavioural evaluation (i.e., $>24 \mathrm{hrs}$ after fluoxetine injection and training). These tests revealed that injection of fluoxetine caused a selective increase in spontaneous electrical activity in behaviourally conditioned animals (Figure 7). That is, mean CGC spiking activity was significantly raised above 


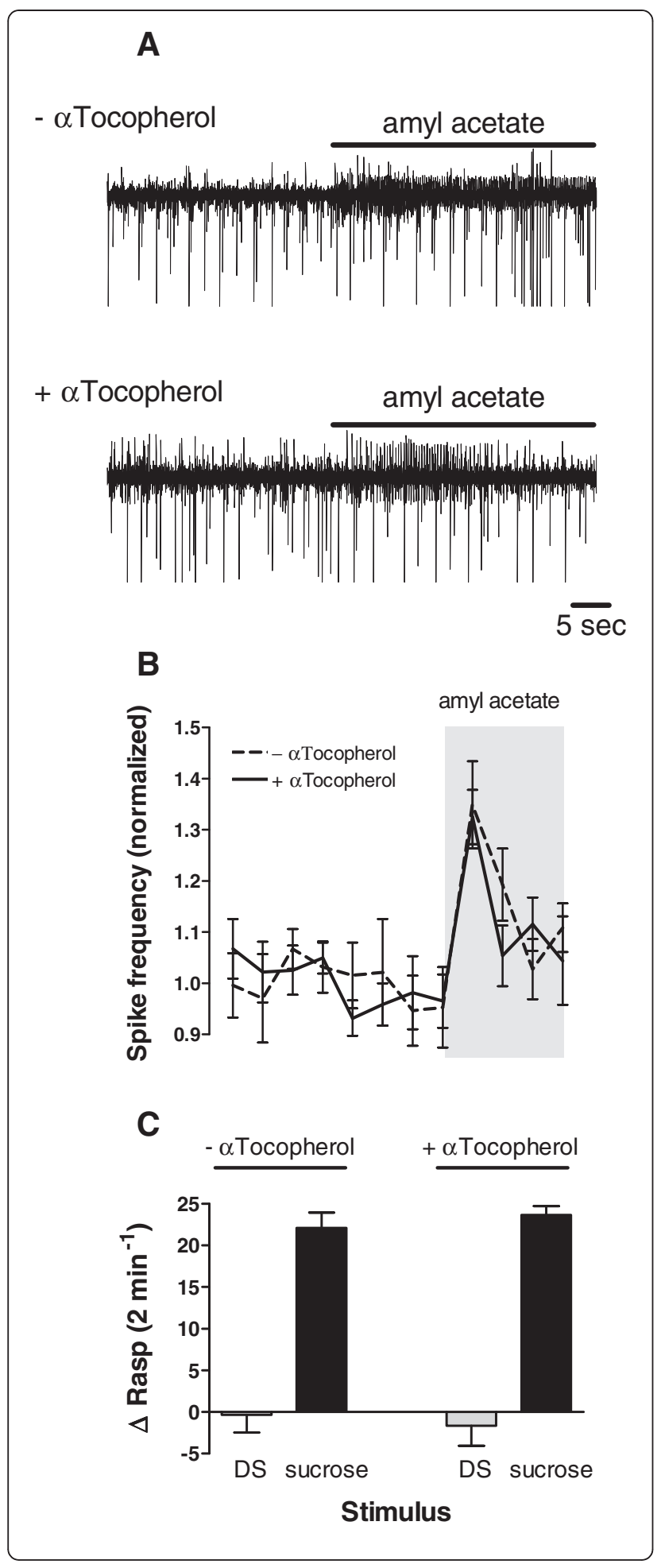

the levels in the other test groups in the fluoxetinetreated behaviourally conditioned animals only (i.e., CSUCS; Figure 7B; Treatment $x$ Training, $F_{1,36}=4.797$, $\mathrm{p}<0.05$; CS-DS vs. CS-UCS within vehicle treated animals, $\mathrm{F}_{1,36}=0.243, \mathrm{p}=0.63$; CS-DS vs. CS-UCS within
Figure 5 Effect of dietary a-tocopherol supplementation on chemosensory and motor function in senior animals. A. Examples of extracellular recording of afferents in the superior lip nerve before and after application of n-amyl acetate ( 4 ppm) of senior animals with dietary supplementation of vehicle only $(-$ aTocopherol; top trace) or a-tocopherol (+ aTocopherol; bottom trace). B. Average action potential frequency (bin size $30 \mathrm{sec}$ ) of afferents in superior lip nerve 4 minutes before and 2 minutes during amyl acetate application. There is no difference in response upon n-amyl acetate application between the two different treatment groups $\mathbf{C}$. Average change in the number of rasps evoked by application of pond water (DS) or sucrose (0.4\%). Only sucrose induced a robust but similar response in senior animals fed with dietary supplementation of vehicle only (- aTocopherol) or atocopherol (+ aTocopherol).

fluoxetine-treated animals, $\left.\mathrm{F}_{1,36}=4.797, \mathrm{p}<0.05\right)$. In addition, fluoxetine induced a marked depolarization of CGCs in both behaviourally conditioned and disturbance control animals that was not observed in their vehicletreated counterparts (Figure 7C; Mann-Whitney, Treatment $\mathrm{x}$ Training, $\mathrm{Z}=-4.826, \mathrm{p}<0.0001$; CS-DS vs. CS-UCS within vehicle treated animals, $Z=-0.359$, $\mathrm{p}=0.72$; CS-DS vs. CS-UCS within fluoxetine-treated animals, $\mathrm{Z}=0.420, \mathrm{p}=0.67$ ).

\section{Discussion}

In the current study we show; 1- A single session, five trial classical appetitive reward-conditioning procedure induced robust associative LTM in mature animals in the first quartile of their lifespan but failed to induce such memory in animals in the last quartile of their lifespan; 2- Appetitive LTM formation correlated with resting membrane potential depolarization of modulatory interneurons (CGCs) with a critical function in the expression of appetitive LTM; 3- CGCs of senior animals fired significantly fewer action potentials and were significantly hyperpolarized relative to their younger counterparts in CNSs dissected from both behaviourally conditioned and control animals; 4- Dietary supplementation of senior animals with $\alpha$-tocopherol reversed the effect of age on action potential activity and resting membrane potential of CGCs in a behavioural conditioning-independent manner yet failed to restore appetitive LTM function; 5- Injection of senior animals with the SSRI fluoxetine reversed the effect of age on resting membrane potential of CGCs in a behavioural conditioning-independent manner while raising CGC electrical activity in behaviourally conditioned animals and restored appetitive LTM function.

\section{Relation to previous work on appetitive LTM conditioning in Lymnaea stagnalis}

The current data are consistent with and corroborate several previous observations. First, by reproducing the 


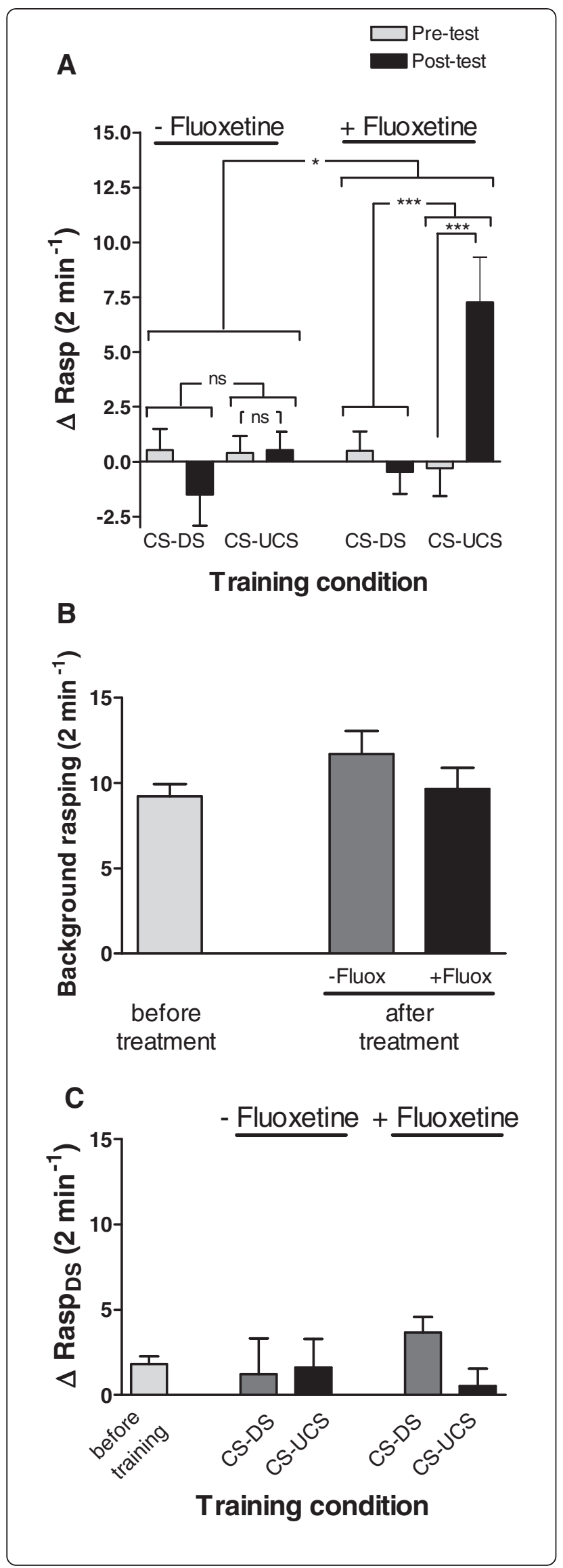

Figure 6 Effect of fluoxetine treatment on LTM performance in senior animals. A. Long-term memory assessment of senior snails following treatment with fluoxetine (+ Fluoxetine) or vehicle only (- Fluoxetine). Fluoxetine treatment significantly improved LTM performance in conditioned (CS-UCS) senior snails. In contrast, vehicle only treated conditioned animals showed no indication of LTM. B. Comparison of spontaneous background rasping rates reveals no significant differences between animals treated with fluoxetine (+ Fluox) or vehicle only (-Fluox). C. Comparison of rasping response after application of the disturbance stimulus reveals no significant differences between unconditioned (CS-DS) and conditioned (CS-UCS) animals regardless whether they were treated with fluoxetine (+ Fluox) or vehicle only (-Fluox).

${ }^{*}=p<0.05,{ }^{* * *}=p<0.001$, ns $=$ non-significant.

results from an earlier study [6], the current data demonstrate that appetitive LTM impairment is a recurrent and reproducible phenomenon in aging Lymnaea. Moreover, the current results corroborate Kemenes et al.'s conclusion that CGC depolarization is a key factor in the expression of LTM in non-senescent animals [24]. Also, the observations that senior CGCs are electrically less excitable, with substantially lower action potential activity as compared to their junior counterparts and that this reduced electrical activity can be reversed by treatment with the lipophilic anti-oxidant $\alpha$-tocopherol duplicates results we obtained on a different type of identified neuron in Lymnaea $[3,6]$. Thus, the current data support our idea that declining electrical excitability due to oxidative stress in the neuronal lipid-domain is a defining feature of the neurophysiology of aging in these snails. Lastly, our finding that fluoxetine treatment reversed the effect of age on CGC electrophysiology and appetitive LTM function complements Patel et al.'s observations that CGC's (pre)synaptic functions change with age $[26,27]$.

\section{Neurophysiological mechanisms of age-associated appetitive LTM impairment}

The data presented here provide compelling evidence that CGC synaptic terminals are a key locus of the weakening appetitive LTM performance of aging Lymnaea. Moreover, our results suggest that this phenomenon has multiple dimensions. For instance, it is clear that chemosensory behavioural conditioning of old animals does not induce the delayed-onset, persistent depolarization of the CGCs critical for the presynaptic facilitation underlying expression of appetitive LTM [24]. Although the precise neural and signal transduction pathways involved in this process are still under investigation, it appears that behavioural-conditioning invoked cAMP/ PKA-dependent recruitment of a persistent TTXinsensitive $\mathrm{Na}^{+}$current $\left(I_{\mathrm{Na}(\mathrm{p})}\right)$ is the first and critical step in a multi-tiered process leading to the facilitation of cerebral-buccal interneurons relaying peripheral 


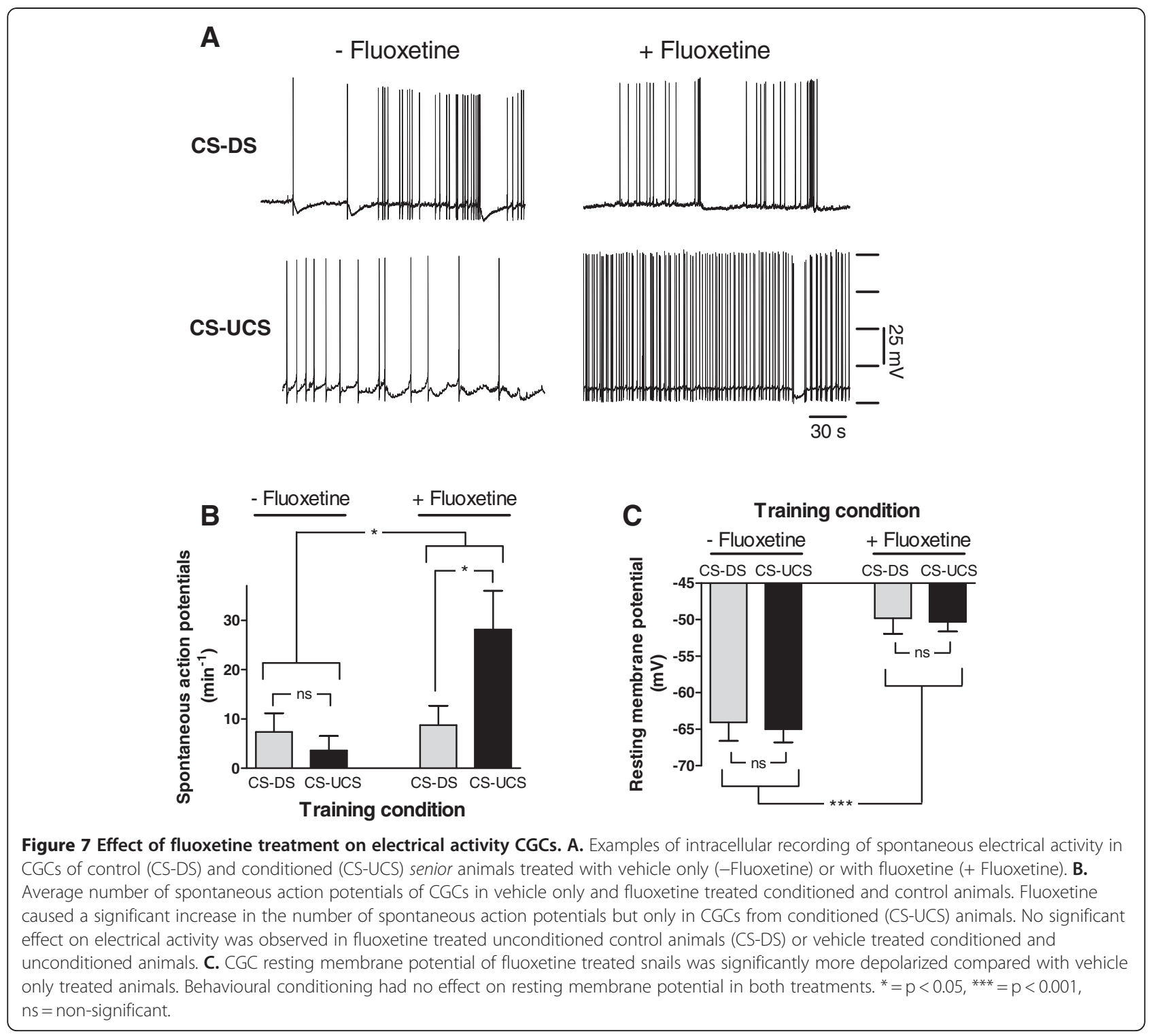

chemosensory information to the buccal feeding circuit [24,28-30]. It is evident that this mechanism fails in old animals. Although we currently do not know for sure why this happens, some scenarios appear more likely than others. For instance, there is little evidence for peripheral chemosensory deficits in old animals this study, $[6,31]$. Therefore, although we can at this time not entirely exclude a role for primary chemosensory insufficiency as an explanation for age-associated appetitive LTM impairment it seems highly unlikely. Likewise, in contrast to other investigators working with this model system [23], we never found any evidence for major motor deficiencies in the feeding behaviour of old animals [6]. Nonetheless, the notion that primary chemosensory and motor functions of the buccal feeding complex appear to be essentially spared over the course of aging does not exclude the possibility that old animals integrate chemosensory information in a different fashion and relay this information in a different way to the feeding network. In fact, the literature does provide some precedents for that idea $[6,27,31]$. Moreover, such a scenario also appears consistent with the dramatically diminished excitability of aged CGCs, although it is not immediately evident how to reconcile this hypothesis with the observation that $\alpha$-tocopherol did not restore LTM function in senior animals despite reversing the effects of age on CGC excitability.

\section{Mechanisms of CGC membrane depolarization}

We show that both dietary supplementation of $\alpha$ tocopherol and injection with fluoxetine caused depolarization of CGCs in aged animals. Because of their 
very different biological activities, this effect likely involves different mechanisms. As a chain-breaking lipophilic antioxidant $\alpha$-tocopherol has the ability to intercept lipid peroxidation cascades and prevent further oxidation of the plasma membrane [32,33]. Our previous work has implicated lipid-peroxidation as a starting point for as yet incompletely understood mechanisms involved in the control of neuronal excitability $[3,19]$. For instance, various species of ion channels involved in the regulation of neuronal excitability are subject to redox-modulation [3439]. Alpha-tocopherol could thus directly affect intrinsic excitability of neurons by interfering with ion channel oxidation status. Alternatively, because of its amphiphilic nature and structural asymmetry, $\alpha$-tocopherol has the capacity to effect plasma membrane architectural changes, particularly changes in membrane curvature [40]. Membrane curvature is a variable in many membraneassociated processes including ion channel gating that could be a factor in the electrophysiological effects of $\alpha$ tocopherol described here [41,42]. In addition, although we have not yet fully identified the signalling pathways involved, our own work indicates that $\alpha$-tocopherol can intervene in neuronal lipid signalling processes that are apparently associated with reduced excitability of aged neurons $[3,19]$. Thus, $\alpha$-tocopherol likely operates primarily on plasmamembrane- or lipid signalling-associated determinants of intrinsic neuronal excitability $[3,19]$. Fluoxetine on the other hand, may induce CGC membrane depolarization by augmenting autoregulatory feedback mechanisms. The cells express one or more of the $\mathrm{G}_{\mathrm{i}^{-}}$ coupled serotonin receptor subtypes that in the case of serotonin-dependent presynaptic facilitation of sensory pathways in the Aplysia californica gill-withdrawal reflex model have been implicated in the closure of S-like $\mathrm{K}^{+}$ channels [43-47]. Parenthetically, there is some evidence that these channels, members of the 4 transmembrane, 2 pore-region (4TM2P) family of background $\mathrm{K}^{+}$channels are directly inhibited by fluoxetine and its metabolites $[47,48]$. It should be noted however that recent studies suggest that fluoxetine's spectrum of pharmacological activities in the Lymnaea nervous system extends beyond the compound's "classical SSRI activity. [26,49]. Therefore, further studies are required to examine the mechanisms through which fluoxetine ameliorates the effects of age on neural- and behavioural plasticity in this model system.

\section{Why does dietary supplementation of a-tocopherol fail to alleviate age-associated LTM impairment while it did reverse the effects of age on neuronal excitability?}

One of the remarkable aspects of our results is the differential ability of $\alpha$-tocopherol and fluoxetine to reverse both electrophysiological and behavioural effects of age. That is, the results show that dietary supplementation of $\alpha$-tocopherol successfully reversed the effect of age on
CGC resting membrane potential and electrical activity but failed to alleviate LTM impairment in old animals whereas a single injection of fluoxetine reversed both electrophysiological and behavioural effects of age. Alpha-tocopherol's inability to restore LTM function in senior animals is particularly puzzling since experimental depolarization of CGCs in semi-intact preparations from, presumably, non-senescent animals was shown to be sufficient to replicate the effect of behavioural conditioning on feeding network responses to peripheral chemosensory stimuli [24]. Thus, we are left with the conclusion that in Lymnaea neurons, treatment with $\alpha$-tocopherol may reverse low-excitability conditions associated with old age but does not bring about facilitation of neurotransmitter release while fluoxetine is, at least in the case of the CGCs, apparently capable of both. We currently have no definitive explanation for this dissimilarity. It is possible that fluoxetine, being a SSRI, augments CGC synaptic efficacy through enhancing postsynaptic serotonergic mechanisms. In addition, as discussed above, it is possible that fluoxetine induce CGC membrane depolarization by augmenting autoregulatory feedback mechanisms. That is, there is some evidence suggesting that serotonin acts as an excitatory autotransmitter in CGCs through mechanisms analogous to the serotonindependent presynaptic facilitation of sensory pathways previously described in the Aplysia californica gillwithdrawal reflex model [43-47]. Also, the literature hints at an alternative presynaptic mechanism. That is, Shomrat et al. [50] demonstrated that serotonin facilitates induction of activity-dependent long-term potentiation in Octopus vulgaris. In addition, Hart et al. [51] recently implicated synapsin, a protein critical in the regulation of vesicle recruitment and pre-synaptic neurotransmitter release, in 5-HT-dependent long-term presynaptic facilitation in sensorimotor synapses of the gastropod Aplysia californica through the modulation of vesicle release mechanisms. This finding is particularly interesting in the context of the present study, since Patel et al. [26] reported that fluoxetine reverses age-associated effects of neurotransmitter release by CGCs. Although it is not yet clear through which mechanism(s) synapsin promotes secretory vesicle release probability, these two studies suggest that, in contrast to $\alpha$-tocopherol, fluoxetine promotes presynaptic facilitation of CGCs and thereby improves LTM function in our aged animals through a depolarization-independent presynaptic mechanism. One of the intriguing implications of this idea is that synapsins may be a target for treatment of age-associated cognitive impairment. Further studies are needed to answer this question and to examine whether this principle can be generalized to different types of chemical synapses.

An alternative explanation for $\alpha$-tocopherol's failure to reproduce the presynaptic facilitation of CGC synaptic 
terminals required for the expression of appetitive LTM in old animals worthwhile considering centers on the possibility of an age-associated breakdown of background $\mathrm{Ca}^{2+}$ signalling mechanisms. Modulation of neurotransmitter release through variation of presynaptic resting membrane potential proceeds through small changes in intracellular free $\mathrm{Ca}^{2+}$ concentrations arising from subthreshold activation of voltage-gated $\mathrm{Ca}^{2+}$ channels [52]. There is evidence suggesting that a similar mechanism may contribute to presynaptic facilitation in Lymnaea CGCs [24]. Changes in intracellular $\mathrm{Ca}^{2+}$ homeostasis are quite a common symptom of neuronal aging [53]. It is therefore possible that the differential effectiveness of $\alpha$-tocopherol and fluoxetine in restoration of appetitive LTM in old animals could be a reflection of the fact that the former depends mostly on background $\mathrm{Ca}^{2+}$ signalling mechanisms whereas the latter, as discussed above, may not.

Taken together, whereas the current data establish the CGC as a major neurophysiologic correlate of ageassociated LTM dysfunction in Lymnaea and does reiterate the significance of lipid (per)oxidation in neuronal excitability decline with age, it is evident that further investigations are needed to resolve exact causal relations between one and the other.

\section{Conclusions}

Although we have not yet identified the precise molecular mechanisms, our data leaves little doubt that the CGCs are a locus of age-associated LTM-impairment in Lymnaea. As such, our study identifies failure of experience-induced, depolarization-dependent presynaptic facilitation of the CGCs as a very probable neurobiological correlate of this memory defect. Moreover, the current results further underpin the conclusion from our previous work that lipid-peroxidation, likely through activation of phospholipase $\mathrm{A}_{2}\left(\mathrm{PLA}_{2}\right)$, is a pivotal factor in the gradual decline in neural- and behavioral plasticity associated with the normal aging process $[3,19]$. It is important to recognize that we do not stand alone in this conclusion. The significance of lipid-peroxidation in aging in phylogenetically quite diverse model systems has been acknowledged for a long time [54-57]. Moreover, recent reports explicitly associate $\mathrm{PLA}_{2}$-activity with age-associated cognitive deficits and neurodegenerative diseases [58]. Thus, we believe that the phenomena described here reflect the actions of universal, evolutionary conserved mechanism of neuronal aging originating in lipid peroxidation. It is evident from the work presented here that Lymnaea's feeding behavior and underlying neural system provides a superbly traceable model to dissect the neurobiological substrate of learning and memory impairment associated with normal aging.

\section{Methods}

\section{Animal populations}

Animals were bred and raised under constant conditions as previously described $[3,6,19,59]$. Snails were raised in house under strictly controlled ambient conditions (light:dark 12:12, ambient temperature $18-19^{\circ} \mathrm{C}, \mathrm{pH} 7.8$ 7.9). Water used in the facility was sourced from a reverse osmosis system and reconditioned to a conductivity of $\sim 450 \Omega . c m$ through the addition of Instant Ocean salts at $1 \mathrm{~g} / \mathrm{US}$ Gallon (i.e., artificial pond water; Aquarium Systems USA). Calcium concentration was kept at saturation level $\left(\sim 60 \mathrm{mg} / \mathrm{L}\right.$ as $\left.\mathrm{CaCO}_{3}\right)$ through the addition of calcium carbonate (light powder; EMD analytics, Gibbstown, New Jersey) to the tanks. In addition, animals had continuous access to sterilized cuttlefish (Sepia officinalis) bone (2-3 per tank). Unless stated differently, animals in this study were fed a routine diet consisting of Romaine lettuce and Aquamaxcarniverous Grower 600 trout pellets ad libitum (Purina Mills LLC, St. Louis, Missouri).

Survival characteristics of the populations were continuously monitored and evaluated using previously established methods based on the Weibull failure model (Table 1) [60,61]. Experimental animals were taken at random from different age-synchronized healthy, populations with survival percentages at the time of sampling ranging from $>99 \%$ to $<25 \%$ survival (Table 1 ). For the purpose of this study, old ("senior") animals (1823 months of age) are defined as animals falling in the $25 \%$ or less survival range, while sexually mature young adult ("junior") animals (5-7 months of age) fall into the $95 \%$ or more survival range. Survival characteristics as defined by Weibull model parameters (see Table 1) of all populations used in this study closely aligned with those used in earlier studies $[3,6,19]$.

The use and care of animals conformed to the University of Calgary Animal Care and Use Policy which adheres to the guidelines, policies and standards of the Canadian Council on Animal Care (CCAC), the Canadian Association of Laboratory Animal Medicine (CALAM), standards of Veterinary Care, and the Alberta Veterinary Association (AVMA) professional codes and standards.

\section{Training and testing procedures Preparation}

Behavioural conditioning was done on 3 to 4 sets of animals each constituted of equal numbers of individuals in an experimental groups (the number of replicate training sessions depended on the sample size required) using a non-aversive appetitive classical conditioning protocol modified from Hermann et al. [6]. Snails from each of the two age cohorts were sampled at random. For identification purposes a small indelible label was glued to the 
Table 1 Parameter estimates of two-parameter Weibull failure model fitted to the survival characteristics of Lymnaea stagnalis populations used in the present study

\begin{tabular}{lllccc}
\hline Population & $\boldsymbol{a}$ (error) & $\boldsymbol{c}$ (error) & $\boldsymbol{s} \cdot \mathbf{1 0}^{-\mathbf{2}}$ (error) & \% survival at sampling & age range (month) \\
\hline Junior 1 & $490(9.9)$ & $3.7(0.25)$ & $-0.26\left(1.37 \cdot 10^{-2}\right)$ & $>95 \%$ & $5-7$ \\
Senior 1 & $440(8.3)$ & $4.3(0.29)$ & $-0.34\left(1.19 \cdot 10^{-2}\right)$ & $<25 \%$ & $21-22$ \\
Senior 2 & $550(9.6)$ & $4.0(0.29)$ & $-0.25\left(1.56 \cdot 10^{-2}\right)$ & $<25 \%$ & $21-22$ \\
Senior 3 & $550(7.4)$ & $4.5(0.29)$ & $-0.28\left(1.91 \cdot 10^{-2}\right)$ & $<25 \%$ & $22-23$ \\
Senior 4 & $570(9.6)$ & $3.8(0.28)$ & $-0.23\left(1.66 \cdot 10^{-2}\right)$ & \\
\hline
\end{tabular}

Note: " $a$ " and " $c$ " are parameters of the two-parameter Weibull model (" $a$ " is median age; " $c$ " is the shape parameter; " $s$ " is slope of tangent of survival curve at
median age).

shell of each snail or marked with indelible marker. Except during testing and training periods, the snails were housed in a common 100-L "home" tank filled with artificial pond water. Food was withheld starting $48 \mathrm{hrs}$ prior to the first pre-training test and for the remainder of the training and post-training testing.

\section{Testing procedures}

Animals from different age and experimental groups were individually tested in random order. On day 1, prior to behavioural conditioning each snail was individually tested for their natural response to the administration of pond water, the disturbance stimulus (DS), as well as the conditional stimulus (CS) n-amyl acetate (4 ppm final concentration, Figure 1A, "Pre-training test"; see also [6]). Tests were performed using 100-ml translucent polystyrene beakers $(4.5 \mathrm{~cm}$ diameter $)$, filled with $80 \mathrm{~mL}$ of water taken from the snail's home tank. After transfer into the beakers, the snails were allowed to acclimatize for $15 \mathrm{~min}$ before testing commenced. Testing involved counting the number of rasps over two consecutive periods of $2 \mathrm{~min}$, the first period starting with gentle administration of the DS $(10 \mathrm{ml}$ artificial pond water), the second period starting with the administration of the CS (10 $\mathrm{ml} \mathrm{n}$-amyl acetate solution). To facilitate observation, the test beakers were elevated by translucent plastic stands and were surrounded by mirrors to ensure continuous view of the buccal mass and radula of the snails during testing. A test response was calculated by taking the difference between the number of rasps counted during the second period minus the number counted during the first period (i.e., $\Delta$ Rasp $=$ rasps after CS - rasps after DS). To correct for both differences in background rasping activity and potential application artefacts, the pre-training tests were performed in duplicate with $>1 \mathrm{hr}$ interval, and behavioural responses were calculated as the average of both $\Delta$ Rasp (i.e., $\Delta$ Rasp $_{\text {pre-test }}=$ average $\Delta$ Rasp pre-test 1 and $\Delta$ Rasp $_{\text {pre-test }} 2$ ). To determine in some experiments non-associative rasping behaviour, we also counted for a period of 2 minutes the number of rasps before DS application. Thus the disturbance (DS) response is: $\Delta$ Rasp $_{D S}=$ rasps after DS - rasps before DS. After completion of a test, snails were gently rinsed and returned to their home tanks. A single posttraining test was performed on day 3 (i.e., 24 hrs after training) following identical procedures as described for the pretesting above (Figure 1A).

\section{Training procedure}

Snails were trained in a single day, multi-trial forwarddelay conditioning format (Figure 1A; modified from [6]). Sucrose (final concentration of $0.4 \% \mathrm{wt} / \mathrm{vol}$ ) served as the unconditioned stimulus (UCS) and n-amyl acetate (4 ppm final concentration) as the conditioned stimulus (CS). To control for potential behavioural effects of fluid addition, a disturbance control in which the UCS was paired with the DS (i.e., pond water) was implemented. Snails were randomly assigned to either the CS-UCS ("conditioned") or the CS-DS (unconditioned "control") group and trained "en masse". Training was performed in 1-L polypropylene beakers containing $480 \mathrm{ml}$ clean artificial pond water. After transfer into the training beakers, the snails were allowed to acclimatize for $60 \mathrm{~min}$. Both "control" and "conditioned" groups received $120 \mathrm{~mL}$ of the CS solution, followed $15 \mathrm{~s}$ later by $120 \mathrm{ml}$ of the UCS ("conditioned" group) or $120 \mathrm{ml}$ of the DS ("control" group). After $2 \mathrm{~min}$, the beakers containing the snails were drained and gently rinsed with clean pond water and the snails were readied for their next training trial by re-placing them in the 1-L polypropylene beakers holding $480 \mathrm{ml}$ clean artificial pond water. After $11 \mathrm{~min}$ and $45 \mathrm{sec}$ the training procedure was repeated (Figure 1A). Snails received a total of 5 training procedures on a single day before being returned to their "home" tank. During training and testing, snails were at all times fully submerged. Care was taken to ensure that pretesting, training and post-testing commenced at the same time of day for each group and training and testing always occurred in the same location. "Conditioned" and "control" snails were always tested and trained concurrently.

\section{Anti-oxidant supplementation}

Snails 16-17 month of age were sampled at random from their parent populations, labelled, housed in a 
common 100-L "home" tank and food deprived for 48 hrs before being submitted to behavioural assessments. After the post-test, animals were transferred to $15-\mathrm{L}$ polypropylene containers filled with artificial pond water and subdivided in 12 equal-sized compartments created with materials allowing free flow of water that contained one snail each. This arrangement allowed for individual feeding of snails, yet maintained otherwise uniform environmental conditions for the different test groups. Snails were randomly split into two test groups. Both groups were fed lettuce ad libitum. In addition, one group received agar pellets $(3 \% \mathrm{w} / \mathrm{v})$ containing $\alpha$-tocopherol dissolved in $\mathrm{EtOH}(0.13 \% \mathrm{v} / \mathrm{v} ; 0.08 \mathrm{mg}$ $\alpha$-tocopherol/pellet) plus Nutrafin Basix fish flakes (0.04 $\mathrm{mg} /$ pellet), whereas the other group received agar pellets containing Nutrafin Basix fish flakes only (Note, EtOH is evaporated during the preparation of the agar pellets). Each snail received a single pellet every 48 hrs. After a period of 2 months, the snails were transferred to the common 100-L "home" tank, food deprived for $48 \mathrm{hrs}$ and subsequently trained and tested to re-assess LTM performance as described before, with each snail staying within their previously assigned groups (i.e., either CS + UCS or CS + DS).

\section{Fluoxetine treatment}

Fifty microliters of fluoxetine dissolved in ultrapure $\mathrm{H}_{2} \mathrm{O}$ was injected into the animal creating an approximate final concentration of $100 \mathrm{nM}$. Another set of animals received an injection of $50 \mu$ l ultrapure $\mathrm{H}_{2} \mathrm{O}$ only (vehicle control). Injection was done $2 \frac{1}{2} \mathrm{hrs}$ prior to the start of the first training session. All solutions were injected through the foot directly into the hemocoel with a microliter syringe and a $30 \mathrm{G}$ needle. Animals were behaving normally within a few minutes after injection.

\section{Unconditioned sucrose induced feeding behaviour}

To determine whether $\alpha$-tocopherol caused a chemosensory and/or motor deficiency, naïve (unconditioned) animals were tested for their feeding response upon sucrose application. Tests were performed using 100-ml translucent polystyrene beakers $(4.5 \mathrm{~cm}$ diameter $)$, filled with $80 \mathrm{~mL}$ of water taken from the snail's home tank. After transfer into the beakers, the snails were allowed to acclimatize for $15 \mathrm{~min}$ before testing commenced. Testing involved counting the number of rasps over three consecutive periods of $2 \mathrm{~min}$, the second period starting with gentle administration of artificial pond water $(10 \mathrm{ml})$ a disturbance stimulus (DS), the third period starting with the administration of sucrose solution $(0.4 \% \mathrm{w} / \mathrm{v}$ final concentration). The disturbance response was calculated by taking the difference between the number of rasps counted during the second period minus the number counted during the first period (i.e.,
$\Delta$ Rasp disturbance $=$ rasps after DS - rasps after pond water). The sucrose response was calculated by taking the difference between the number of rasps counted during the third period minus the number counted during the second period (i.e., $\Delta$ Rasp surcose $=$ rasps after sucrose - rasps after DS).

\section{Electrophysiology \\ Intracellular recordings}

Both conditioned and control snails were dissected and subjected to electrophysiological evaluation within 48 hrs of final behavioural assessment (post-training test). To this end, snails were de-shelled using curved forceps and subsequently anaesthetized in a $25 \%$ Listerine solution. All dissections and experiments were carried out in a hydroxyethylpiperazine ethanesulphonic acid (HEPES) -buffered saline (HBS) composed of (in mM) $51.3 \mathrm{NaCl}, 1.7 \mathrm{KCl}, 4.1 \mathrm{CaCl}_{2}, 1,5 \mathrm{MgCl}_{2}$ and 10 HEPES (pH 7.9). CNSs were dissected as described previously [60]. Dissected CNSs were pinned down in an elastomer covered recording chamber filled with HBS. To provide access to the Cerebral Giant Cells (CGCs), the outer layer of connective tissue surrounding the cerebral ganglia were removed with fine forceps without the use of proteolytic enzymes [62,63]. Intracellular recordings of the CGCs were done by means of microelectrode recording techniques with the use of either Axoclamp 2A or Axoclamp 2B, (Axon Instruments, Burlingame, CA) operated in discontinuous current clamp mode at sample rates ranging from $2-4 \mathrm{kHz}$ depending on electrode settling characteristics. Amplifier output was filtered at $1 \mathrm{kHz}$ and digitized at $5 \mathrm{kHz}$ using a Digidata 1322A AD/DA converter (Axon Instruments, Burlingame, CA). Data acquisition was carried out with Axoscope sampling software (version 9.0, Axon Instruments) and subsequently analyzed using Clampfit software (version 9.0 Axon Instruments). Borisilicate glass electrodes (TW150F, World Precision Instruments, Sarasota, FL) were filled with a solution of $0.5 \mathrm{M}$ potassium acetate $\left(\mathrm{CH}_{3} \mathrm{COOK}\right)$ and $0.01 \mathrm{M}$ potassium chloride $(\mathrm{KCl})$. DC resistance of the electrodes ranged between 10-25 M $\mathrm{M}$.

\section{Extracellular recordings}

Extracellular recordings of lip sensory neurons were made from the superior lip nerve by means of a suction electrode in a semi-intact preparation as described by Straub et al. [64]. Briefly, after snails were anaesthetized with $25 \%$ Listerine solution, the central nervous system was exposed by means of a small dorsal incision in the midline of the head region. The head of the snail containing the lips, tentacles and buccal mass, plus the CNS was carefully dissected from the rest of the body. Subsequently the right superior lip nerve was cut as close to 
the CNS as possible. The remaining peripheral nerves were cut close to their muscle innervation zone and the CNS was discarded. The preparation was pinned down in a Sylgard coated dish, and the superior lip nerve was drawn into a glass microelectrode with a diameter just large enough to accommodate the nerve. A perfusion system was used to continuous apply saline or n-amyl acetate $(4 \mathrm{ppm})$ with the outflow placed close to the lip/ mouth region. Extracellular signals were amplified using an in-house build extracellular amplifier, bandpass filtered at $10-1000 \mathrm{~Hz}$ and digitized at $5 \mathrm{kHz}$ sampling rate using a Digidata 1322A AD/DA converter (Axon Instruments, Union City, CA). Recordings were analyzed offline using template-matching waveform recognition software (Spike2, version 4.02a, Cambridge, England). Template selection criteria were set to ignore waveforms that occurred less frequently than 1 in 50 events. From these data overall peristimulus histograms were generated with a bin size of 30 seconds. The data was normalized to the average activity of the period prior to amyl acetate application.

\section{Statistical analysis}

Behavioural data was analyzed using repeated measures ANOVA. Spontaneous activity of the CGCs was analyzed by means of a factorial ANOVA. Explicit hypotheses were tested using linear contrast techniques unless indicated differently in the text. Compliance with parametric assumptions was confirmed for each data set submitted to ANOVA using both graphical (probability plots applied to raw data and residuals) and analytical techniques (Kolmogorov-Smirnov one-sample test for normality, F-max test). Nonparametric tests were used to analyze CGC resting membrane potential (MannWhitney $U$ test or Kruskal-Wallis). Throughout the text, average and data dispersion are expressed as arithmetic means and standard error of the mean (SEM).

\begin{abstract}
Abbreviations
LTM: Long-term memory; DS: Disturbance stimulus; CS: Conditioned stimulus; UCS: Unconditioned stimulus; PLA2: Phospholipase A2; HBS: HEPES buffered saline; CGC: Cerebral giant cell; SSRI: Selective serotonin reuptake inhibitor.
\end{abstract}

\section{Competing interests}

The authors declare that they have no competing interests.

\section{Authors' contributions}

Conceived research program WCW. Conceived and designed the experiments: SNW, TER, PMH, WCW. Performed the experiments: SNW, TER, PMH. Analyzed the data SNW, TER, PMH, WCW. Wrote the paper: SNW, TER, $\mathrm{PMH}, \mathrm{WCW}$. All authors read and approved the final manuscript.

\section{Acknowledgements}

The work was supported by a National Science and Engineering Research Council (NSERC) Canada operating grant to WCW and NSERC (Canada) graduate scholarship to TER.

Received: 17 April 2012 Accepted: 13 August 2012

Published: 17 August 2012

\section{References}

1. Fukui HH, Xiu L, Curtsinger JW: Slowing of age-specific mortality rates in Drosophila melanogaster. Exp Gerontol 1993, 28(6):585-599.

2. Horiuchi J, Saitoe M: Can flies shed light on our own age-related memory impairment? Ageing Res Rev 2005, 4(1):83-101.

3. Watson SN, Nelson MA, Wildering WC: Redox agents modulate neuronal activity and reproduce physiological aspects of neuronal aging. Neurobiol Aging 2012, 33(1):149-161.

4. Gallagher M, Rapp PR: The use of animal models to study the effects of aging on cognition. Annu Rev Psychol 1997, 48:339-370.

5. Rosenzweig ES, Barnes CA: Impact of aging on hippocampal function: plasticity, network dynamics, and cognition. Progress in Neurobiol 2003, 69(3):143-179

6. Hermann PM, Lee A, Hulliger S, Minvielle M, Ma B, Wildering WC: Impairment of long-term associative memory in aging snails (Lymnaea stagnalis). Behav Neurosci 2007, 121(6):1400-1414.

7. Burke SN, Barnes CA: Neural plasticity in the ageing brain. Nat Rev Neurosci 2006, 7(1):30-40.

8. Disterhoft JF, Oh MM: Learning, aging and intrinsic neuronal plasticity. Trends Neurosci 2006, 29(10):587-599.

9. Disterhoft JF, Oh MM: Alterations in intrinsic neuronal excitability during normal aging. Aging Cell 2007, 6(3):327-336.

10. Klaassen $L$, Janse $C$, van der Roest M: Multiple synaptic connections of a single neuron change differentially with age. Neurobiol Aging 1998, 19(4):341-349.

11. Catala A: A synopsis of the process of lipid peroxidation since the discovery of the essential fatty acids. Biochem Biophys Res Commun 2010, 399(3):318-323.

12. Cini $M$, Moretti $A$ : Studies on lipid peroxidation and protein oxidation in the aging brain. Neurobiol Aging 1995, 16(1):53-57.

13. Spiteller $\mathrm{G}$ : Is lipid peroxidation of polyunsaturated acids the only source of free radicals that induce aging and age-related diseases? Rejuv Res 2010, 13(1):91-103.

14. Harman D: Aging: a theory based on free radical and radiation chemistry. J Gerontol 1956, 11(3):298-300.

15. Harman D: The free radical theory of aging. Antioxid Redox Signal 2003, 5(5):557-561.

16. Paradies G, Petrosillo G, Paradies V, Ruggiero FM: Mitochondrial dysfunction in brain aging: role of oxidative stress and cardiolipin. Neurochem Int 2011, 58(4):447-457.

17. Bishop NA, LU T, Yankner B: Neural mechanisms of ageing and cognitive decline. Nature 2010, 464(7288):529-535.

18. Dröge W, Schipper HM: Oxidative stress and aberrant signaling in aging and cognitive decline. Aging Cell 2007, 6(3):361-370.

19. Watson SN, Wright N, Hermann PM, Wildering WC: Phospholipase A2: The key to reversing long-term memory impairment in a gastropod model of aging. Neurobiol Aging 2012, doi:10.1016/j.neurobiolaging.2012.02.028. Mar 27 [Epub ahead of print].

20. Audesirk TE, Alexander JE Jr, Audesirk GJ, Moyer CM: Rapid, nonaversive conditioning in a freshwater gastropod. I. Effects of age and motivation. Behav Neural Biol 1982, 36(4):379-390.

21. Yeoman MS, Kemenes G, Benjamin PR, Elliott CJ: Modulatory role for the serotonergic cerebral giant cells in the feeding system of the snail, Lymnaea. II. Photoinactivation. J Neurophysio/ 1994, 72(3):1372-1382.

22. Yeoman MS, Brierley MJ, Benjamin PR: Central pattern generator interneurons are targets for the modulatory serotonergic cerebral giant cells in the feeding system of Lymnaea. J Neurophysiol 1996, 75(1):11-25.

23. Yeoman MS, Patel BA, Arundell M, Parker K, O'Hare D: Synapse-specific changes in serotonin signalling contribute to age-related changes in the feeding behaviour of the pond snail, Lymnaea. J Neurochem 2008, 106(4):1699-1709.

24. Kemenes I, Straub VA, Nikitin ES, Staras K, O'Shea M, Kemenes G, Benjamin PR: Role of delayed nonsynaptic neuronal plasticity in long-term associative memory. Curr Biol 2006, 16(13):1269-1279.

25. Benjamin PR, Staras K, Kemenes G: A systems approach to the cellular analysis of associative learning in the pond snail Lymnaea. Learn Mem 2000, 7(3):124-131.

26. Patel BA, Arundell M, Parker KH, Yeoman MS, O'Hare D: Microelectrode investigation of neuroneal ageing from a single identified neurone. Phys Chem Chem Phys 2010, 12(34):10065-10072. 
27. Patel BA, Arundell M, Allen MC, Gard P, O'Hare D, Parker K, Yeoman MS: Changes in the properties of the modulatory cerebral giant cells contribute to aging in the feeding system of Lymnaea. Neurobiol Aging 2006, 27(12):1892-1901.

28. Nikitin ES, Kiss T, Staras K, O'Shea M, Benjamin PR, Kemenes G: Persistent sodium current is a target for CAMP-induced neuronal plasticity in a state-setting modulatory interneuron. J Neurophysiol 2006, 95(1):453-463.

29. Nikitin ES, Vavoulis DV, Kemenes I, Marra V, Pirger Z, Michel M, Feng J O'Shea M, Benjamin PR, Kemenes G: Persistent sodium current is a nonsynaptic substrate for long-term associative memory. Curr Biol 2008, 18(16):1221-1226

30. Nikitin ES, Koshunova T, Balaban PM, Kemenes G: Learning-induced alterations of axonal spike processing and long-term associative memory in Lymnaea [abstract]. In Neuroscience Meeting Planner 2011, 766.25. Washington, DC: Society for Neuroscience; 2011. Online.

31. Arundell M, Patel BA, Straub V, Allen MC, Janse C, O'Hare D, Parker K, Gard $P R$, Yeoman MS: Effects of age on feeding behavior and chemosensory processing in the pond snail, Lymnaea stagnalis. Neurobiol Aging 2006, 27(12):1880-1891.

32. Liebler DC, Kling DS, Reed DJ: Antioxidant protection of phospholipid bilayers by alpha tocopherol control of alpha tocopherol status and lipid peroxidation by ascorbic-acid and glutathione. J Biol Chem 1986, 261(26):12114-12119.

33. Wagner BA, Buettner GR, Burns CP: Vitamin E slows the rate of free radical-mediated lipid peroxidation in cells. Arch Biochem Biophys 1996, 334(2):261-267.

34. Gamper N, Zaika O, Li Y, Martin P, Hernandez CC, Perez MR, Wang AY, Jaffe DB, Shapiro MS: Oxidative modification of M-type $\mathrm{K}(+)$ channels as a mechanism of cytoprotective neuronal silencing. EMBO J 2006, 25(20):4996-5004.

35. Giese KP, Storm JF, Reuter D, Fedorov NB, Shao LR, Leicher T, Pongs O, Silva AJ: Reduced $\mathrm{K}+$ channel inactivation, spike broadening, and afterhyperpolarization in Kvbeta1.1-deficient mice with impaired learning. Learn Mem 1998, 5(4-5):257-273.

36. Hool LC, Corry B: Redox control of calcium channels: from mechanisms to therapeutic opportunities. Antioxid Redox Signal 2007, 9(4):409-435.

37. Joksovic PM, Nelson MT, Jevtovic-Todorovic V, Patel MK, Perez-Reyes E, Campbell KP, Chen CC, Todorovic SM: CaV3.2 is the major molecular substrate for redox regulation of T-type $\mathrm{Ca} 2+$ channels in the rat and mouse thalamus. J Physiol 2006, 574(Pt 2):415-430.

38. Nelson MT, Joksovic PM, Su P, Kang HW, Van Deusen A, Baumgart JP, David LS, Snutch TP, Barrett PQ, Lee JH, Zorumski CF, Perez-Reyes E, Todorovic SM: Molecular mechanisms of subtype-specific inhibition of neuronal T-type calcium channels by ascorbate. J Neurosci 2007, 27(46):12577-12583.

39. Ruppersberg JP, Stocker M, Pongs $O$, Heinemann SH, Frank R, Koenen M: Regulation of fast inactivation of cloned mammalian IK(A) channels by cysteine oxidation. Nature 1991, 352(6337):711-714.

40. Atkinson J, Epand RF, Epand RM: Tocopherols and tocotrienols in membranes: a critical review. Free Radic Biol Med 2008, 44(5):739-764.

41. Borjesson SI, Parkkari T, Hammarstrom S, Elinder F: Electrostatic tuning of cellular excitability. Biophys J 2010, 98(3):396-403.

42. Lee KJ: Effects of hydrophobic mismatch and spontaneous curvature on ion channel gating with a hinge. Phys Rev E Stat Nonlin Soft Matter Phys 2005, 72(3 Pt 1):031917.

43. Kyriakides MA, McCrohan CR: Effect of putative neuromodulators on rhythmic buccal motor output in Lymnaea stagnalis. J Neurobiol 1989, 20(7):635-650

44. Walcourt-Ambakederemo A, Winlow W: 5-HT receptors on identified Lymnaea neurones in culture: pharmacological characterization of 5-HT2 receptors. Gen Pharmacol 1994, 25(6):1079-1092.

45. Walcourt-Ambakederemo A, Winlow W: 5-HT receptors on identified Lymnaea neurones in culture: pharmacological characterization of 5-HT3 receptors. Gen Pharmacol 1995, 26(3):553-561.

46. Castellucci V, Kandel ER: Presynaptic facilitation as a mechanism for behavioral sensitization in Aplysia. Science 1976, 194(4270):1176-1178.

47. Patel AJ, Honore E, Maingret F, Lesage F, Fink M, Duprat F, Lazdunski M: A mammalian two pore domain mechano-gated S-like $\mathrm{K}+$ channel. EMBO J 1998, 17(15):4283-4290.

48. Kennard LE, Chumbley JR, Ranatunga KM, Armstrong SJ, Veale EL, Mathie A: Inhibition of the human two-pore domain potassium channel, TREK-1, by fluoxetine and its metabolite norfluoxetine. Br J Pharmacol 2005, 144(6):821-829.

49. Getz A, Xu F, Zaidi W, Syed NI: The antidepressant fluoxetine but not citalopram suppresses synapse formation and synaptic transmission between Lymnaea neurons by perturbing presynaptic and postsynaptic machinery. Eur J Neurosci 2011, 34(2):221-234.

50. Shomrat T, Feinstien N, Klein M, Hochner B: Serotonin is a facilitatory neuromodulator of synaptic transmission and "reinforces" long-term potentiation induction in the vertical lobe of Octopus vulgaris. Neurosci 2010, 169:52-64.

51. Hart AK, Fioravante D, Liu RY, Phares GA, Cleary LJ, Byrne JH: Serotoninmediated synapsin expression is necessary for long-term facilitation of the Aplysia sensorimotor synapse. J Neurosci 2011, 31(50):18401-18411.

52. Awatramani GB, Price GD, Trussell LO: Modulation of transmitter release by presynaptic resting potential and background calcium levels. Neuron 2005, 48(1):109-121.

53. Gleichmann M, Mattson MP: Neuronal calcium homeostasis and dysregulation. Antioxid Redox Signal 2011, 14(7):1261-1273.

54. Butterfield DA, Bader Lange ML, Sultana R: Involvements of the lipid peroxidation product $\mathrm{HNE}$, in the pathogenesis and progression of Alzheimer's disease. Biochem Biophys Acta 2010, 1801:924-929.

55. Negre-Salvayre A, Auge N, Ayala V, Basaga H, Boada J, Brenke R, Chapple S, Cohen G, Feher J, Grune T, Lengyel G, Mann GE, Pamplona R, Poli G, Portero-Otin M, Riahi Y, Salvayre R, Sasson S, Serrano J, Shamni O, Siems W, Siow RC, Wiswedel I, Zarkovic K, Zarkovic N: Pathological aspects of lipid peroxidation. Free Radical Res 2010, 44(10):1125-1171.

56. Terzibasi E, Valenzano DR, Benedetti M, Roncaglia P, Cattaneo A, Domenici $L$, Cellerino A: Large differences in aging phenotype between strains of the short lived annual fish Notobranchius furzeri. PlosOne 2008, 3(12): e3866.

57. Maxwell KE, Matthews TR, Sheehy MRJ, Bertelsen RD, Derby CD: Neurolipofuscin is a measure of age in Panulirus argus, the Caribbean spiny lobster, in Florida. Biol Bull 2007, 213(1):55-66.

58. Sanchez-Mejia RO, Newman JW, Toh S, Yu GQ, Zhou Y, Halabisky B, Cissé M, Scearce-Levie K, Cheng IH, Gan L, Palop JJ, Bonventre JV, Mucke L: Phospholipase $\mathrm{A} 2$ reduction ameliorates congitive deficits in a mouse model of Alzheimer's disease. Nature Neursci 2008, 11:1311-1318.

59. Hermann PM, Genereux B, Wildering WC: Evidence for age-dependent mating strategies in the simultaneous hermaphrodite snail, Lymnaea stagnalis (L.). J Exp Biol 2009, 212(19):3164-3173.

60. Janse C, Slob W, Popelier CM, Vogelaar JW: Survival characteristics of the mollusc Lymnaea stagnalis under constant culture conditions: effects of aging and disease. Mech Ageing Dev 1988, 42(3):263-274.

61. Slob W, Janse C: A quantitative method to evaluate the quality of interrupted animal cultures in aging studies. Mech Ageing Dev 1988, 42(3):275-290.

62. Hermann PM, Lukowiak K, Wildering WC, Bulloch AGM: Pronase acutely modifies high voltage-activated calcium currents and cell properties of Lymnaea neurons. Eur J Neurosci 1997, 9(12):2624-2633.

63. Hermann PM, Bulloch AGM: Pronase modifies synaptic transmission and activity of identified Lymnaea neurons. Inv Neurosci 1998, 3:295-304.

64. Straub VA, Stules BJ, Ireland JS, O'Shea M, Benjamin PR: Central localization of plasticity involved in appetative conditioning in Lymnaea. Learn Mem 2004, 11:787-793.

doi:10.1186/1471-2202-13-103

Cite this article as: Watson et al:: Failure of delayed nonsynaptic neuronal plasticity underlies age-associated long-term associative memory impairment. BMC Neuroscience 2012 13:103. 